Revista Voluntas: estudos sobre Schopenhauer - $1^{\circ}$ semestre 2011 - Vol. 2 - No 1 - ISSN: 2179-3786 - pp. 83-94.

\title{
O gênio e o santo na filosofia de Schopenhauer
}

Daniel Quaresma Figueira Soares

Doutorando em Filosofia pela USP

RESUMO: Trata-se de delinear um paralelo entre o gênio e o santo no interior da filosofia de Schopenhauer. Num primeiro momento, serão apresentados dois pontos que aproximam as duas figuras: a suspensão do sofrimento e o conhecimento além do principium individuationis. A seguir, tratar-se-á de buscar aquilo que os distingue radicalmente: a especificidade do santo em relação ao gênio não residirá em sua duração temporal, mas na noção de salvação.

PALAVRAS-CHAVE: gênio; santo; salvação.

ZUSAMMENFASSUNG: Es geht um das Entwerfen Parallele zwischen dem Genie und dem Heiligen in Schopenhauers Philosophie. Als Erstes werden zwei Punkte dargestellt, die beide Figuren näher bringen: die Aufhebung des Leiden und die Erkenntnis jenseits des principium individuationis. Im Anschluss daran wird nach dem gesucht, was sie von Grund auf unterscheidet: die Besonderheit des Heiligen im Vergleich zu dem Genie besteht nicht in seinem temporalen Dauer, sondern in dem Begriff des Heiles.

SCHLÜSSELWÖRTER: Genie; Heilige; Heil.

Schopenhauer inicia Sobre a quádrupla raiz do princípio de razão suficiente anunciando o método que deve ser seguido por toda a filosofia, e mesmo por todo o saber em geral. Baseado em suas duas principais referências filosóficas expressas, Platão e Kant, Schopenhauer nos diz que esse método consiste na satisfação de duas leis: homogeneidade e especificação. Enquanto a homogeneidade seria, em sentido amplo, a busca pelas semelhanças e concordâncias entre objetos aparentemente distintos, a especificação seria a descoberta da diferença entre objetos aparentemente semelhantes. As duas regras deveriam ser aplicadas sempre na mesma medida, e não uma em detrimento da outra.

Pretendemos aqui nos inspirar nesse método anunciado pelo filósofo, a fim de explorar a relação entre duas das principais figuras de sua obra: o gênio e o santo. Ocupando lugar central no livro III do primeiro volume de $O$ mundo como Vontade $e$ Representação, o gênio em Schopenhauer é aquele que contempla a Ideia (a partir da qual a obra de arte é criada). Já o santo, por sua vez, é aquele que realiza a negação da Vontade, tema central do livro IV da principal obra schopenhaueriana.

A intenção de analisar a relação entre o gênio e o santo surgiu a partir de uma passagem do parágrafo 68 d'O mundo. Nela, Schopenhauer afirma que o santo, ao alcançar

${ }^{1}$ SCHOPENHAUER, A. SW III, SG, § 1, p. 11. 
a negação da Vontade pela via do sofrimento, "em sentido ético se tornou genial" 2 [in ethischer Hinsicht genial wird]. Tal afirmação nos levou a suspeitar que entre o conhecimento da Ideia e a negação da Vontade haveria alguma relação essencial ${ }^{3}$.

Isso posto, procuraremos aqui inicialmente analisar essa relação a partir de alguns pontos determinados, evidenciando o que há em comum entre o gênio e o santo; num segundo momento, seguindo a via oposta, procuraremos ressaltar a especificidade de cada um deles face ao outro. Ao final, pretendemos tornar claro como a especificidade do santo em relação ao gênio culmina num tema crucial da filosofia schopenhaueriana: a salvação.

Comecemos por investigar o que há de semelhante entre as figuras do santo e do gênio. A primeira aproximação entre elas terá por base a supressão do sofrimento. Após ter, no livro I de sua obra principal, apresentado um mecanismo do conhecimento do mundo como representação no qual o corpo exerce papel de mediador, na função de objeto imediato, Schopenhauer percorrerá no livro II o caminho para a descoberta do sentido moral do mundo. Será preciso descobrir o que é o mundo além de mera representação do sujeito que conhece, atacando assim a ameaça do solipsismo. Tal sentido só será descoberto quando, a partir de uma inflexão sobre a consciência de si, a vontade será identificada ao corpo próprio, na instituição daquilo que Schopenhauer chamará "verdade filosófica kat' exochén"4. Noutras palavras, o corpo, que no livro I exercia o papel de mediador do conhecimento do mundo como representação, será agora descoberto, por meio de um novo ponto de vista, como objetivação da vontade. Num passo seguinte, lançando mão do (problemático) argumento de analogia, Schopenhauer afirmará que não apenas o corpo próprio, mas todo o mundo como representação deverá ser agora considerado - além de mera representação do sujeito que conhece - objetivação da Vontade. É nessa Vontade que se encontrará o significado moral do mundo.

Porém, a Vontade schopenhaueriana possuirá uma estrutura, por assim dizer, perversa: ela será designada como um querer cego, sem fim (desprovido tanto de

${ }^{2}$ SCHOPENHAUER, A. MVR I, § 68, p. 501.

${ }^{3}$ A relação entre o gênio e o santo já foi explorada também por alguns comentadores. Maria Lúcia Cacciola, por exemplo, aborda o tema em Schopenhauer e a questão do dogmatismo (p. 164-165). Julian Young também se dedica detidamente à questão (YOUNG, J. Schopenhauer, p. 203ss). Alexis Philonenko, por sua vez, afirma que o gênio "é a moralidade imediata" (PHILONENKO, A. Schopenhauer: une philosophie de La tragédie, p. 124). Jair Barboza chega mesmo a afirmar que a contemplação estética constitui um grau inferior de negação da Vontade. Barboza trata da questão tanto em Infinitude subjetiva e estética: natureza e arte em Schelling e Schopenhauer (p. 261ss) quanto em A metafisica do belo de Arthur Schopenhauer (p. 63-64).

${ }^{4}$ SCHOPENHAUER, A. MVR I, § 18, p. 160. 
finalidade quanto de satisfação última, término). Ou seja, a Vontade será apresentada como uma falta incessante, uma atividade que nunca encontra repouso. Partindo dessa configuração íntima da Vontade, a situação do indivíduo na filosofia schopenhaueriana culmina naquilo que usualmente se designa como pessimismo do filósofo.

$\mathrm{O}$ indivíduo em Schopenhauer é constituído pela união entre sujeito do conhecimento e corpo. Tal constituição encontra suas raízes naquilo que o filósofo denomina em Sobre a quádrupla raiz do princípio de razão suficiente o "nó do mundo" [Weltknoten], que consiste na identidade entre sujeito do querer e sujeito do conhecer na autoconsciência ${ }^{5}$. Não sendo mero sujeito do conhecimento, mera "cabeça de anjo alada destituída de corpo" [geflügelter Engelskopf ohne Leib] ${ }^{6}$, esse indivíduo é também sujeito do querer: é atravessado por um corpo que é ele mesmo objetivação da Vontade. Desse modo, o indivíduo será marcado pelo sofrimento por ser constituído a partir de um querer que não conhece satisfação final. Destinado a um querer que nunca encontra sua realização última, a situação do indivíduo será de incessante sofrimento. Eis por que Schopenhauer costuma se valer de imagens como a da roda de Íxion para descrever essa situação:

Pelo tempo em que o querer preenche a nossa consciência, pelo tempo em que estamos entregues ao ímpeto dos desejos com suas contínuas esperanças e temores, por conseguinte, pelo tempo em que somos sujeito do querer, jamais obtemos felicidade duradoura ou paz. E em essência é indiferente se perseguimos ou somos perseguidos, se tememos a desgraça ou almejamos o gozo: o cuidado pela Vontade sempre exigente, não importa em que figura, preenche e move continuamente a consciência. Sem tranquilidade, entretanto, nenhum bem-estar verdadeiro é possível. O sujeito do querer, consequentemente, está sempre atado à roda de Íxion que não cessa de girar, está sempre enchendo os tonéis das Danaides, é o eternamente sedento Tântalo ${ }^{7}$

Dito isso, devemos agora perceber que tanto o gênio quanto o santo realizarão uma função capital no interior da filosofia de Schopenhauer: ambos apresentam momentos nos quais a roda de Íxion será paralisada e a regra do indivíduo, o sofrimento, será suspensa. O gênio e o santo chegam a essa suspensão do sofrimento por meio do afastamento do corpo.

\footnotetext{
${ }^{5}$ Este tema encontra-se no parágrafo 42 de Sobre a quádrupla raiz do princípio de razão suficiente (SCHOPENHAUER, A. SW III, SG, § 42).

${ }^{6}$ SCHOPENHAUER, A. MVR I, $\S 18$, p. 156.

${ }^{7}$ SCHOPENHAUER, A. MVR I, § 38, p. 266.
} 
O gênio é aquele que, no conhecimento da Ideia, dilui a união constitutiva do indivíduo ao suprimir o corpo do mecanismo da intuição. Abandonando sua condição individual, o gênio torna-se o puro sujeito do conhecimento, alheio a qualquer sofrimento ${ }^{8}$.

O santo, por sua vez, ao operar a negação da Vontade, suprime necessariamente de maneira radical seu corpo (que é sinônimo de afirmação da Vontade), culminando num estado de bem-aventurança além de qualquer individualidade ${ }^{9}$. Mais à frente exploraremos o característico desse estado de bem-aventurança oriundo da negação da Vontade.

Sendo o corpo, como objetivação da Vontade, o portador natural do sofrimento do indivíduo, seu afastamento (que não é senão a dissolução da própria condição individual) leva à suspensão do sofrimento. Tanto o gênio quanto o santo conduzem, assim, a uma paralisação da roda de Íxion. Esse é o primeiro ponto, em si mesmo bastante relevante no interior de uma filosofia dita "pessimista", no qual o gênio e o santo se aproximam na obra de Schopenhauer: ambos conseguem paralisar o círculo do sofrimento. Mas há ainda um segundo ponto a ser destacado.

Outro elemento que nos leva a aproximar o gênio e o santo é o modo de conhecimento que está na raiz de ambas as figuras. Tanto o gênio quanto o santo se valem de um conhecimento que atravessa o véu de Maia, superando as barreiras de espaço, tempo e causalidade (formas subordinadas do princípio de razão). Tal conhecimento é condição necessária tanto da genialidade quanto da santidade.

A função característica do gênio é o conhecimento da Ideia, que despreza por completo o quando, o onde e o porquê. Ao realizar uma intuição que ultrapassa o véu de Maia, afastando o corpo e tornando-se puro sujeito do conhecimento, o gênio é capaz de contemplar a unidade arquetípica por trás de todos os fenômenos ${ }^{10}$.

\footnotetext{
8 "A alegria estética no belo consiste em grande parte no fato de que nós, ao entrarmos no estado de pura contemplação, somos por instantes libertos de todo querer, isto é, de todos os desejos e preocupações: por assim dizer nos livramos de nós mesmos. Não somos mais o indivíduo que conhece em função do próprio querer incansável, correlato da coisa isolada, para o qual os objetos se tornam motivos, mas somos o sujeito eterno do conhecer purificado de Vontade, correlato da Ideia. Sabemos que tais momentos, quando, libertos do ímpeto furioso da Vontade, nos elevamos, por assim dizer, acima da densa atmosfera terrestre, são os mais ditosos que se conhece" (SCHOPENHAUER, A. MVR I, § 68, p. 494-495).

9 "Até quais profundezas irão as raízes da individualidade na essência em si do mundo? [Elas] são tão profundas quanto a afirmação da Vontade de viver; ao surgir a negação, cessam essas raízes, pois surgiram com a afirmação" (SCHOPENHAUER, A. Die Welt als Wille und Vorstellung II (Ergänzungen), SW II, Cap. 50, p. 822). Tradução nossa.

10 "Quando não mais consideramos o Onde, o Quando, o Porquê e o Para Quê das coisas, mas única e exclusivamente o seu Quê [...] Quando, por assim dizer, o objeto é separado de toda relação com algo exterior a ele e o sujeito de sua relação com a Vontade, o que é conhecido não é mais a coisa particular enquanto tal, mas a Ideia, a forma eterna, a objetidade imediata da Vontade neste grau" (SCHOPENHAUER, A. MVR I, § 34, p. 246).
} 
Revista Voluntas: estudos sobre Schopenhauer - $1^{\circ}$ semestre 2011 - Vol. 2 - No 1 - ISSN: 2179-3786 - pp. 83-94.

Já o santo, por sua vez, só pode chegar à negação da Vontade se conhecer a unidade íntima entre todos os fenômenos, ultrapassando o véu de Maia. Mesmo que apareçam num espaço e tempo determinados e sob uma determinada relação causal, tais fenômenos são percebidos pelo santo como objetivação de uma mesma e única Vontade ${ }^{11}$.

Assim, tanto o santo quanto o gênio não conhecem mais coisas particulares ou relações. Ambos possuem uma visão para além de qualquer individuação. Schopenhauer deixa claro que o gênio e o santo partem do mesmo conhecimento, por exemplo, em passagens como a do parágrafo 53 d'O mundo:

O autêntico modo de consideração filosófico do mundo, ou seja, aquele que nos ensina a conhecer a sua essência íntima e, dessa maneira, nos conduz para além do fenômeno, é exatamente aquele que não pergunta 'de onde', 'para onde', 'por que', mas sempre e em toda parte pergunta apenas pelo quê do mundo, vale dizer, não considera as coisas de acordo com alguma relação, isto é, vindo a ser e perecendo, numa palavra, conforme uma das quatro figuras do princípio de razão, mas, diferentemente, tem por objeto precisamente aquilo que permanece após eliminar-se o modo de consideração que segue o referido princípio, noutros termos, tem por objeto o ser do mundo sempre igual a si e a aparecer em todas as relações... A fílosofia, como a arte, procede de tal conhecimento. Ora, [...] também é desse conhecimento que procede aquela disposição de espírito, única que conduz à verdadeira santidade e à redenção do mundo ${ }^{12}$

\footnotetext{
11 “Agora, se essa visão através do principii individuationis, ou seja, esse conhecimento imediato da identidade da Vontade em todos os seus fenômenos existe num elevado grau de distinção, de imediato mostra uma influência ainda mais ampla sobre a Vontade. Se aquele véu de Maia, o principium individuationis, é de tal maneira retirado aos olhos de um homem [...] aquele conhecimento do todo e da essência das coisas torna-se quietivo de toda e qualquer volição. Doravante a Vontade efetua uma viragem diante da vida: fica terrificada em face dos prazeres nos quais reconhece a afirmação desta. $\mathrm{O}$ homem, então, atinge o estado de voluntária renúncia, resignação, verdadeira serenidade e completa destituição de Vontade" (SCHOPENHAUER, A. MVR I, § 68, p. 481-482).

${ }^{12}$ SCHOPENHAUER, A. MVR I, § 53, p. 357. Podemos lembrar ainda mais duas passagens nas quais o filósofo explicita que gênio e santo dependem do mesmo conhecimento. No parágrafo 55 d' $O$ mundo: "No homem, por conseguinte, a Vontade pode alcançar a plena consciência de si, o conhecimento distinto e integral da própria essência tal qual esta se espelha em todo o mundo. Em função da existência real desse grau de conhecimento, como vimos no livro precedente, origina-se exatamente a arte. Ao final de nossa consideração, entretanto, ainda veremos que, por intermédio do mesmo conhecimento [durch dieselbe Erkenntnis], é possível uma supressão e autonegação da Vontade em seu fenômeno mais perfeito..." (SCHOPENHAUER, A. MVR I, § 55, p. 373). Ou ainda no parágrafo 60: "É sempre uma exceção se um semelhante decurso de vida sofre uma interferência e, devido a um conhecer independente do serviço da vontade e direcionado à essência do mundo em geral, conduz à demanda pela contemplação estética ou à demanda pela renúncia ética" (SCHOPENHAUER, A. MVR I, § 60, p. 421).
} 
É sobretudo devido a esse conhecimento em comum que Schopenhauer aproxima o santo do gênio ao dizer que o santo torna-se "genial em sentido ético". Ou seja, o santo é genial na medida em que possui o mesmo conhecimento do gênio, uma intuição além das formas subordinadas do princípio de razão, desvendando a ilusão proporcionada pelo véu de Maia.

Por meio de tais semelhanças, somos levados a crer numa aproximação inicial entre o gênio e o santo. Mas será que deveríamos assim concluir, com o jovem Wittgenstein (talvez influenciado por Schopenhauer), que "ética e estética são uma só"13? De modo algum. As aproximações entre eles começam a cessar na medida em que uma primeira ressalva se interpõe: a questão da duração.

Ao conhecer além do véu de Maia, o gênio não permanece em tal conhecimento de modo definitivo. Como atesta frequentemente Schopenhauer, o gênio decai continuamente de seu conhecimento puro, sendo turvado novamente pelos interesses da Vontade. Ou seja, aquela tranquilidade alcançada pela contemplação estética seria apenas efêmera, fugaz ${ }^{14}$. Já a negação da Vontade, quando elevada às suas últimas consequências, conduz o santo à supressão do mundo de modo definitivo, lançando-o no nada (mesmo que um nada relativo). Assim, encontramos aqui aparentemente um primeiro limite para a aproximação entre o gênio e o santo: a contemplação estética é temporalmente limitada, a negação da Vontade não. Essa poderia talvez constituir uma radical distinção entre eles.

Porém, numa visão mais ampla, logo se percebe que essa diferença é ela mesma problemática no interior do sistema schopenhaueriano. Afinal, tal distinção possui como critério central o tempo, a duração temporal. Ora, como forma subordinada do princípio de razão, o tempo não pode servir como critério fidedigno para marcar a especificidade do santo em relação ao gênio.

É certo que o próprio Schopenhauer chega a sugerir em alguns momentos que a função do gênio é temporária, ao passo que a ação do santo é definitiva ${ }^{15}$. Porém, se o

\footnotetext{
${ }^{13}$ WITTGENSTEIN, L. Tractatus Logico-Philosophicus, p. 277.

${ }^{14}$ Após ter apresentado a contemplação estética, afirma Schopenhauer: "Assim que surge novamente na consciência uma relação com a vontade, com a nossa pessoa, precisamente dos objetos intuídos puramente, o encanto chega ao fim. Recaímos no conhecimento regido pelo princípio de razão. Não mais conhecemos a Ideia, mas a coisa isolada, elo de uma cadeia à qual nós mesmos pertencemos. De novo estamos abandonados às nossas penúrias" (SCHOPENHAUER, A. MVR I, § 38, p. 269).

15. Referindo-se ao artista, diz Schopenhauer em $O$ mundo como Vontade e Representação: “... um tal conhecimento não se torna para ele um quietivo da Vontade, não o salva para sempre [auf immer] da vida, mas apenas momentaneamente [auf Augenblicke], contrariamente [...] ao santo que atinge a resignação" (SCHOPENHAUER, A. MVR I, § 52, p. 350). Ao contrapor contemplação estética e negação da Vontade,
} 
critério utilizado para delimitar a diferença entre o gênio e o santo for sua duração, não se poderá ao fim perceber uma real diferença entre eles.

Afinal, o conhecimento da Ideia ocorre por definição fora do tempo. Como já mencionamos, ao conhecer a Ideia, suprimindo o indivíduo e o corpo, o gênio despe-se de todas as formas subordinadas do princípio de razão (espaço, tempo e causalidade). Sendo assim, levando a sério a definição da atividade genial, ao conhecimento da Ideia não poderá jamais ser aplicada a noção de duração: se não há tempo, não há como se falar em duração.

Do mesmo modo, na negação da Vontade ocorre finalmente a negação do mundo em todas as suas formas. Ao negar a Vontade, o santo não pertence mais a qualquer causalidade, espaço ou tempo (formas pertencentes ao mundo como representação). Eis por que a noção de duração não poderia também ser aplicada à negação da Vontade.

Percebemos assim que a duração temporal não pode ser critério de diferenciação entre o gênio e o santo porque tanto a contemplação estética quanto a negação da Vontade estão além de qualquer tempo. Como seria possível distinguir por meio da duração figuras que não pertencem ao tempo? Respeitando o sistema schopenhaueriano, não é possível afirmar que a contemplação realizada pelo gênio possui maior ou menor duração que a negação da Vontade porque nem o gênio nem o santo pertencem ao tempo. A noção de duração não é cabível a eles. Cremos que a distinção entre o gênio e o santo residirá num outro ponto, crucial na filosofia schopenhaueriana.

Embora o gênio e o santo partam ambos daquele conhecimento que ultrapassa o véu de Maia, o gênio detém-se nesse conhecimento e o santo, por sua vez, efetua a negação da Vontade, conduzindo-se a um domínio além de qualquer conhecimento. O objetivo do gênio é alcançado no interior do conhecer: contemplar além do véu de Maia é, para ele, um fím em si mesmo. O conhecimento é condição necessária e suficiente da realização do gênio: "Aquele conhecimento profundo, puro e verdadeiro da essência do mundo se torna um fim em si [Zweck an sich] para o artista, que se detém nele"16. Já o santo, embora parta

diz o filósofo: "Daí podermos supor quão bem-aventurada deve ser a vida de um homem cuja vontade é neutralizada não apenas por instantes [auf Augenblicke], como na fruição do belo, mas para sempre [auf immer], sim, inteiramente extinguida" (SCHOPENHAUER, A. MVR I, § 68, p. 495).

${ }_{16}$ SCHOPENHAUER, A. MVR I, § 52, p. 350. É preciso deixar claro que também o homem comum, que não é produtor de obras de arte, possui genialidade em algum grau: "O gênio é a capacidade preponderante de apreender as Ideias das coisas por intuição contemplativa e puramente objetiva, a qual só acontece na medida em que é abandonado o modo de consideração conforme o princípio de razão [...] Entretanto, a capacidade para tal conhecimento tem de encontrar-se também, em menores e diversos graus, em todos os homens, porque do contrário eles seriam incapazes de fruir as obras de arte, como o são de produzi-las, e não poderiam possuir em geral nenhuma receptividade para o belo e o sublime" [SCHOPENHAUER, A. Metafisica do 
do mesmo conhecimento como condição necessária, irá além e encontrará a negação da Vontade ao ultrapassar todo e qualquer conhecimento. Schopenhauer afirma expressamente que a negação da Vontade ultrapassa também o conhecimento (afinal, basta lembrarmos que conhecimento é servo da Vontade):

Já que conhecemos o intelecto apenas como um órgão da afirmação da Vontade, não vemos por que ele deveria ser trazido à tona [hervorbringen] após a supressão [Aufhebung] dessa Vontade; nada podemos também dizer sobre o sujeito dessa supressão, pois só conhecemos o sujeito de modo positivo em seu ato [actus] contrário, o 'velle' [querer] ${ }^{17}$

A intuição que ultrapassa o véu de Maia é condição necessária mas não suficiente da negação da Vontade, ao contrário do que ocorre na contemplação estética ${ }^{18}$. O santo vale-se daquele conhecimento para chegar à supressão da Vontade; porém, ao chegar a ela, abre mão do próprio conhecimento - lembrando-nos a famosa imagem da escada de Wittgenstein $^{19}$. Ao negar a Vontade, o santo coloca-se além de qualquer relação entre sujeito e objeto, forma geral da representação e pilar de todo o conhecimento ${ }^{20}$. Já o gênio, embora se desfaça das formas subordinadas do princípio de razão (conhecendo a Ideia além de qualquer espaço, tempo e causalidade), permanece preso à cisão sujeito-objeto.

Assim, embora o caminho que conduz à negação da Vontade exija aquela intuição que ultrapassa o véu de Maia, a redenção estará além de qualquer conhecimento. Mas o que

Belo, p. 82-83]. Assim, o característico da genialidade não se expressa na criação artística, mas no mero conhecimento da Ideia, capacidade possuída, em maior ou menor grau, por qualquer homem.

${ }^{17}$ SCHOPENHAUER, A. SW V, P/P II, § 161, p. 369. Tradução nossa. No capítulo 48 dos Suplementos, o filósofo afirma que não devemos supor a existência de um conhecimento superior porque nosso conhecimento já é ele mesmo capaz de conduzir a Vontade à autonegação e supressão. Por meio disso, "a individualidade, e por conseguinte a inteligência, como simples instrumento da natureza individual (isto é, animal), é eliminada [wegfällt]". E continua Schopenhauer: “... o conhecimento tem sua origem na Vontade, refletindo sua afirmação e servindo a seus fins, ao passo que a verdadeira salvação [Heil] repousa na negação da Vontade... [por isso] vemos todas as religiões, em seu ápice, conduzirem ao misticismo e aos mistérios, isto é, à escuridão e ao velado, indicando simplesmente um espaço vazio de conhecimento, o ponto no qual todo conhecimento necessariamente cessa [alle Erkenntnis notwendig aufhört]" (SCHOPENHAUER, A. SW II, WWV II, capítulo 48, p. 781-782. Tradução nossa).

${ }^{18}$ Como afirma Jair Barboza: “... o conhecimento clarividente do santo é, propriamente dizendo, 'somente meio' para a negação do querer, ao contrário do gênio, que nele permanece" (BARBOZA, J. Infinitude subjetiva e estética: natureza e arte em Schelling e Schopenhauer, p. 270).

19 "Deve, por assim dizer, jogar fora a escada após ter subido por ela" (WITTGENSTEIN, L. Tractatus Logico-Philosophicus, p. 281). Diz Schopenhauer: “... a supressão do querer é a última obra da inteligência, que até então servia aos propósitos [Zwecken] daquele querer. Por isso, mesmo a inteligência mais perfeita possível pode ser apenas um degrau de passagem [Übergangsstufe] a um ponto que não pode ser alcançado por nenhum conhecimento" (SCHOPENHAUER, A. SW II, WWV II, capítulo 48, p. 782. Tradução nossa).

20 “...'êxtase, iluminação, união com Deus etc'. Esses estados, porém, não podem ser chamados propriamente de conhecimento, já que neles não está presente a forma sujeito e objeto" (CACCIOLA, M. Schopenhauer e a questão do dogmatismo, p. 159). 
caracterizará, afinal, a negação da Vontade realizada pelo santo? O que será esse domínio além de todo conhecimento? Aqui devemos nos voltar novamente para as palavras de Schopenhauer num momento crucial de sua exposição, justamente a transição do livro III ao livro IV de $O$ mundo como Vontade e Representação:

Aquele conhecimento profundo, puro e verdadeiro da essência do mundo se torna um fim em si para o artista, que se detém nele. Eis por que um tal conhecimento não se torna para ele um quietivo da Vontade, não o salva para sempre da vida, mas apenas momentaneamente, contrariamente [...] ao santo que atinge a resignação. Ainda não se trata, para o artista, da saída da vida mas apenas de um consolo [Trost] ocasional em meio a ela; até que sua força aí incrementada, finalmente cansada do jogo, volte-se para o sério $[\text { Ernst }]^{21}$

Por um lado, o consolo e o jogo. Por outro, a salvação e o sério. Não se detendo no mero conhecimento, apenas o santo adentrará o domínio do sério, alcançando finalmente a salvação. É isso o que, em ultima instância, apontará para sua distinção radical em relação ao gênio. Procuremos agora delinear essa noção de salvação e, com ela, a especificidade do santo na filosofia schopenhaueriana.

A negação da Vontade não se restringirá a um conhecimento porque será marcada por uma ação: o santo realiza um ato de não querer ${ }^{22}$. Não é por outro motivo que vemos Schopenhauer insistir que a salvação só pode ser apresentada através de exemplos da vida de santos. Ao lançar-se no nada (mesmo que relativo), a negação da Vontade não pode mais ser exposta por meio da abstração, como requer o conhecimento filosófico ${ }^{23}$. Ao contrário da contemplação estética, que era ainda um conhecimento (mesmo que conhecimento das Ideias, e não ordinário), a ação negadora da Vontade, por ser ato e não conhecimento, não poderá mais ser exposta abstratamente pelo discurso filosófico.

Schopenhauer não deixa dúvidas de que a ação humana seria o tema "mais importante" de sua filosofia, sendo o ato de negação da Vontade o ápice de seu sistema. Ao abrir o livro IV de $O$ mundo como Vontade e Representação, diz o filósofo:

A última parte de nossa consideração proclama a si mesma como a mais séria [ernsteste] de todas, pois concerne às ações do homem, objeto que afeta de maneira imediata cada um de nós e a ninguém pode ser algo

\footnotetext{
${ }^{21}$ SCHOPENHAUER, A. MVR I, § 52, p. 350.

22 “A negação da Vontade de viver não estabelece, de modo algum, a aniquilação de uma substância, mas um mero ato [actus] de não querer (SCHOPENHAUER, A. SW V, P/P II, § 161, p. 368. Tradução nossa).

${ }^{23}$ Referindo-se à negação da Vontade, diz Cacciola: "Sua plena expressão só acontece na ação, e não por meio de conceitos abstratos. Por isso a filosofia só apresenta esse fato de um modo pálido, já que seu domínio é a abstração" (CACCIOLA, M. Schopenhauer e a questão do dogmatismo, p. 165).
} 
alheio ou indiferente [...] Esse lado do mundo deve provar-se como o mais significativo $[$ wichtigste $]$ de todos $[\ldots]^{24}$.

Adentrar o domínio do "sério" é finalmente colocar a questão crucial da salvação ou perdição, algo que ainda não encontrava lugar na metafísica do belo. Adentrar o domínio do "sério" é colocar em questão o valor de uma existência: "Aqui, quando se trata do valor ou ausência de valor da existência [Wert oder Unwert eines Daseins], da salvação ou da perdição [Heil oder Verdammnis]..." ${ }^{25}$.

É por conseguir suprimir definitivamente um mundo radicado no sofrimento do indivíduo (um mundo marcado pela finitude, pelo querer jamais realizado) que o santo se torna aquele que alcança a salvação. Poderíamos dizer que o gênio apresentava com a contemplação da Ideia apenas um consolo, ao passo que o santo apresenta a redenção. Um dos termos mais usados por Schopenhauer para se referir à noção de salvação é Heil. Quando usado como adjetivo, o mesmo termo transmite a ideia de saúde, cura, restabelecimento. Ou seja, tudo se passa como se a negação da Vontade fosse definitivamente a cura para a doença vivida pelo indivíduo como sofrimento, e não apenas um paliativo.

Não há dúvidas de que a filosofia schopenhaueriana possui uma vertente pessimista. O mundo é sofrimento, diz o filósofo de Danzig. Porém, o santo aponta para a possibilidade de recusa radical desse mundo, libertando-se da Vontade insaciável. A salvação em Schopenhauer deve ser pensada também no âmbito da libertação. Se não há em geral liberdade no mundo fenomênico, a salvação surge justamente como exceção: ao contrário da contemplação estética, a negação da Vontade é uma ação efetivamente livre, a única "contradição do fenômeno consigo mesmo"26. É certo que não podemos dizer que, para o autor do escrito Sobre a liberdade da Vontade, todos os homens (como fenômenos) são livres. Porém, poderíamos talvez dizer que cada homem (diferentemente de todos os demais fenômenos da Vontade) traz consigo a possibilidade de libertação, efetivada apenas quando, numa espécie de graça, a salvação é alcançada ${ }^{27}$.

\footnotetext{
${ }^{24}$ SCHOPENHAUER, A. MVR I, $\S 53$, p. 353-354.
}

${ }^{25}$ SCHOPENHAUER, A. MVR I, § 53, p. 353.

26 “... a liberdade, do contrário jamais se mostrando no fenômeno, pois pertence exclusivamente à coisa-em-si, pode neste caso entrar em cena no próprio fenômeno, ao suprimir a essência subjacente ao seu fundamento, embora ele mesmo perdure no tempo; surge daí uma contradição do fenômeno consigo mesmo, expondo desse modo o estado de santidade e autoabnegação" (SCHOPENHAUER, A. MVR I, § 55, p. 373).

27 Após mencionar aquele estado de santidade, diz o filósofo: “... todo o exposto simplesmente indica de maneira geral como o homem se diferencia de todos os demais fenômenos da Vontade, devido ao fato de a liberdade, ou seja, a independência do princípio de razão, que cabe de maneira exclusiva à Vontade como 
Assim, embora haja relevantes convergências entre suas funções, sobretudo em relação ao conhecimento - condição necessária a ambos - e à paralisação do sofrimento, o gênio e o santo possuem diferenças centrais. E a principal delas não nos parece ser sua duração (afinal, levada a sério a letra de Schopenhauer, tanto o gênio quanto o santo estão fora do tempo), mas a noção de salvação.

No capítulo 49 dos Suplementos, intitulado $A$ ordem da salvação [Die Heilsordnung], Schopenhauer refere-se à negação da Vontade como o "propósito da existência" ${ }^{28}$ [Zweck des Daseins]. É nesse domínio, pertencente ao "sério", que o santo se coloca e o gênio não. $\mathrm{O}$ santo em Schopenhauer deve ser pensado sempre como constituinte do campo da redenção, da salvação. O gênio, por sua vez, deve ser pensado como pertencente ao âmbito do consolo (como atesta aquela transição do livro III para o livro IV d'O mundo). Apenas o santo efetua o "único e radical meio de cura [Heilmittel] da doença contra a qual todos os outros meios são anódinos, meros paliativos [Palliativmittel]"29.

Portanto, mesmo que se possa aproximar pontualmente as figuras do gênio e do santo, não devemos jamais perder de vista a especificidade da função exercida pelo santo no interior da filosofia de Schopenhauer: a salvação. É ela que leva a filosofia schopenhaueriana a ultrapassar o âmbito do consolo e adentrar o do sério, colocando em questão não mais a mera alegria desinteressada, mas a libertação, a cura, o valor e propósito da existência.

\section{Referências}

SCHOPENHAUER, A. Sämtliche Werke (org. Löhneysen) em 5 volumes. Stuttgart/Frankfurt am Main: Suhrkamp, 1986. Über die vierfache Wurzel des Satzes vom zureichenden Grunde. SW III. Die Welt als Wille und Vorstellung II. SW II.

. Parerga und Paralipomena II. SW V.

coisa-em-si e contradiz o fenômeno, poder no seu caso possivelmente também entrar em cena no fenômeno, no qual então a liberdade necessariamente se expõe como uma contradição do fenômeno consigo mesmo. Nesse sentido, não apenas a Vontade em si, mas até mesmo o homem devem ser denominados livres, e assim diferenciados de todos os demais seres" (SCHOPENHAUER, A. MVR I, § 55, p. 373).

${ }^{28}$ SCHOPENHAUER, A. SW II, WWV II, capítulo 49, p. 813ss.

${ }^{29}$ SCHOPENHAUER, A. MVR I, § 65, p. 462. 
Editora Unesp, 2005.

. O mundo como Vontade e como Representação. Tradução de Jair Barboza. São Paulo: . Metafísica do Belo. Tradução de Jair Barboza. São Paulo: Editora Unesp, 2001.

BARBOZA, J. A metafisica do belo de Arthur Schopenhauer. São Paulo: Humanitas/Fapesp, 2001.

. Infinitude subjetiva e estética: natureza e arte em Schelling e Schopenhauer. São Paulo: Editora Unesp, 2005.

CACCIOLA, M. L. Schopenhauer e a questão do dogmatismo. São Paulo: Edusp/Fapesp, 1994.

PHILONENKO, A. Schopenhauer: une philosophie de la tragédie. Paris: Vrin, 1999.

WITTGENSTEIN, L. Tractatus Logico-Philosophicus. São Paulo: Edusp, 2001. Tradução de Luiz Henrique Lopes dos Santos.

YOUNG, J. Schopenhauer. London: Routledge, 2005.

Recebido: 25/01/11

Received: 01/25/11

Aprovado: $15 / 06 / 11$

Approved: 06/15/11 